\title{
Connection between ENSO phenomena and solar and geomagnetic activity
}

\author{
M. A. Nuzhdina \\ Astronomical Observatory of Kiev National T. Shevchenko University, Kiev, Ukraine
}

Received: 5 February 2001 - Revised: 6 June 2001 - Accepted: 8 June 2001

\begin{abstract}
Connections between El Niño - Southern Oscillation (ENSO) phenomena and indices of solar activity and geomagnetic disturbance were investigated. Spectral analysis of the ENSO-data was carried out. Oscillations with periods of about 11-12, 5-6, 2-3 years were found. Correlative and cross-spectral analysis was carried out to estimate connections between ENSO data, and solar and geomagnetic indices. Functions of coherency and phase were calculated.
\end{abstract}

\section{Introduction}

ENSO phenomena are a result of complex interaction between the atmosphere and the hydrosphere in the tropical Pacific (Enfield, 1989; Phillander, 1990; Rasmusson and Carpenter, 1982). El Niño and Southern Oscillation (SO) phenomena are considered to be hydrospheric and atmospheric parts of ENSO. An El Niño event is traditionally related to periodic water-warming in the eastern equatorial Pacific. The water-warming is preceded by weakening of the strong easterly wind that blows, usually from the coast of Peru and Equador, along the equatorial Pacific. The cold phase of El Niño is named La Niña. La Niña does not accompany every El Niño. El Niño occurs every three to seven years (Enfield, 1989).

The SO is an oscillation with opposite phase to sea level atmospheric pressure in the east and the west Pacific (Philander, 1990; Rasmusson and Carpenter, 1982). The eastward displacement of the atmospheric heat sources and large-scale change in the global atmospheric circulation occurs during El Niño. As a result, global climatic anomalies and weather disturbances take place in regions far removed from the tropical Pacific.

El Niño - Southern Oscillation phenomena are considered mainly to be internal cycle of positive and negative feedback within the coupled ocean-atmosphere climatic system

Correspondence to: M. A. Nuzhdina

(mn@aoku.freenet.kiev.ua) in the tropical Pacific (Graham and White, 1988; McCreary, 1983; Zebiak and Cane, 1987). However, the notion that ENSO variability results only from an internal feedback process is still highly contentious and a number of external forcing mechanisms have been proposed. Solid earth geophysicists assume that ENSO may possibly be physically connected with seismic events in the Pacific bottom (Walker, 1988, 1995). The possibility of a relation between El Niño events and the quasi-biennial oscillations (QBO) in $50 \mathrm{mb}$ zonal wind was discussed by Angell (1992). El Niño tends mainly to be associated with the east-wind maximum. A Southern Oscillation model was constructed successfully in a paper by Diamantides (1998). The author considers the 11 -year cycle of solar activity to be the cycle, which modulates the long-time dynamics of SO during 100 years (18901990).

We assume that solar activity and a disturbance of the Earth's magnetic field may be considered as an external force for excitement of ENSO variability. The purpose of this paper is to show a connection between ENSO phenomena and solar activity as well as between ENSO and geomagnetic disturbances.

\section{Data}

Sea Surface Temperature (SST) in some regions of the Tropical Pacific is used as an index for El Niño. Four data series of SST (NINO 1 + 2, NINO 3, NINO 4, and NINO $3+4$ ) correspond to four regions. SO index (SOI) is the difference between the standardized data of Sea Level Pressure (SLP) between Tahiti and Darwin (Australia). Locations of El Niño regions as well as Tahiti and Darwin are shown in Table 1.

The following data series were used in the paper:

- Monthly SST anomalies for four regions of El Niño and monthly data of SOI from 1950 to 1999 . Temporal dynamics of ENSO data are shown in Fig. 1. Nine El Niño events were observed from 1950 up to now: 1951- 
Table 1. Correlation between El Niño and SOI yearly data $(\mathrm{N}=49$; lag $=0)$. Locations of El Niño regions as well as Tahiti and Darwin are shown

\begin{tabular}{|c|c|c|c|c|c|}
\hline & NINO $1+2$ & NINO 3 & NINO 4 & NINO $3+4$ & SOI \\
\hline $\begin{array}{l}\text { NINO } 1+2 \\
(0-10 \mathrm{~S} ; 80-90 \mathrm{~W})\end{array}$ & - & 0.92 & 0.56 & 0.76 & -0.70 \\
\hline $\begin{array}{l}\text { NINO } 3 \\
(5 \mathrm{~N}-5 \mathrm{~S} ; 90-150 \mathrm{~W})\end{array}$ & 0.92 & - & 0.80 & 0.94 & -0.85 \\
\hline $\begin{array}{l}\text { NINO } 4 \\
(5 N-5 \text { S; } 150 \mathrm{~W}-160 \mathrm{E})\end{array}$ & 0.56 & 0.80 & - & 0.93 & -0.90 \\
\hline $\begin{array}{l}\text { NINO 3 + } 4 \\
(0-10 \mathrm{~S} ; 80-90 \mathrm{~W})\end{array}$ & 0.76 & 0.94 & 0.93 & - & -0.92 \\
\hline $\begin{array}{l}\text { SOI } \\
\text { (Tahiti: } 17.5 \mathrm{~S} ; 150 \mathrm{~W} \text { ) } \\
\text { (Darwin: } 12.5 \mathrm{~S} ; 131 \mathrm{E} \text { ) }\end{array}$ & -0.70 & -0.85 & -0.90 & -0.92 & - \\
\hline
\end{tabular}

$\mathrm{dt}, \operatorname{deg} \mathrm{C}$

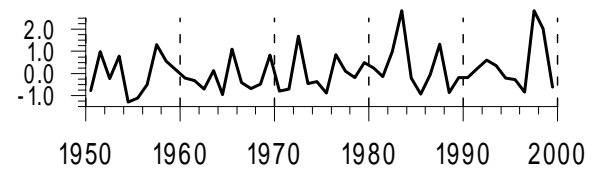

$d t, \operatorname{deg} C$

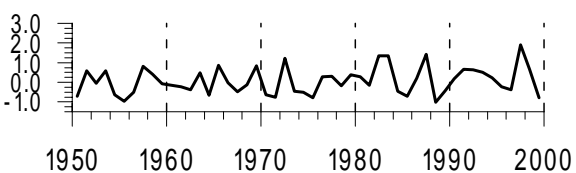

$\mathrm{dt}$, deg C

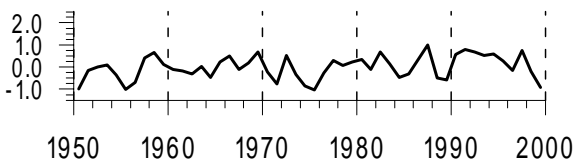

$\mathrm{dt}, \operatorname{deg} \mathrm{C}$

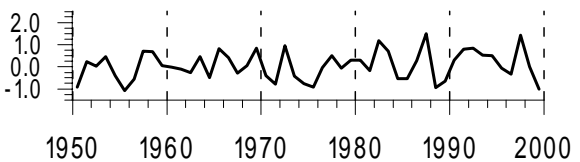

$\mathrm{dp}, \mathrm{mb}$

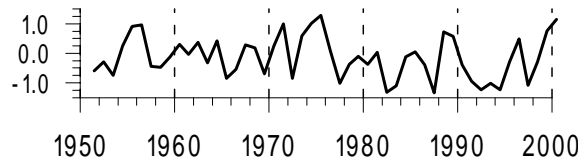

Fig. 1. El Niño and SOI yearly data sets; dt-temperature yearly anomaly; dp-pressure yearly anomaly.

1953 (M - Moderate), 1957-58 (S - Strong), 1965 (M), 1972-73 (S), 1976 (M), 1982-83 (VS - Very Strong), 1987 (M), 1990-95 (M), 1998 (VS). The strongest El Niño in 20-th century was observed at 1982-83, the longest-lived one was occurred in 1990-95 (Trenberth and Hoar, 1996).
- of Ap-planetary index of geomagnetic disturbance from 1950 to 1999 . The ap-index is derived from $\mathrm{Kp}$ geomagnetic index. Daily Kp-index is the sum of local K-indices for 13 geomagnetic observatories in the middle geomagnetic latitudes.

- Wolf-number (sunspot number) as solar activity index.

All data series were taken from INTERNET.

\section{Analysis and results}

Correlation between El Niño and SOI data is shown in Table 1. Correlation is highest between NINO 3, NINO 4 and NINO $3+4$ due to partial overlapping of regions. Thus, the results obtained for NINO $3+4$ data are applicable used for NINO 3 and NINO 4 data. El Niño and SOI data are changing during a time in opposite phase without any lag.

3.1 Comparison of low-frequency variations of ENSO data with Ap-index and Wolf-number data

Spectral analysis of above-mentioned yearly data sets (mean yearly values) was carried out with the aid of the Maximum Entropy Method (MEM). MEM has a major drawback; namely the estimate of significance of peaks is not reliable. It has been suggested that the area under a peak corresponds to the power of the signal (Lacoss, 1971). So, MEM is used to show possible peaks only. That is enough in this case. Two main spectral bands in ENSO data, short-period variations with periods range from 2 to 7 years and long-period oscillations with periods from 10 to 23 years, were found. The spectrum of the Ap-index data reveals spectral bands with periods 6-8, 9-12 and 15-21 years. The Wolf-number spectrum includes 5-9, 9-1-3 and 23-29-year lines (Fig. 2).

Low-frequency variations of ENSO data were compared with dynamics of solar activity and geomagnetic disturbances. Preliminarily, ENSO and Ap-index data were filtered by a Butterworth low frequency filter (BWF) with cut-off 


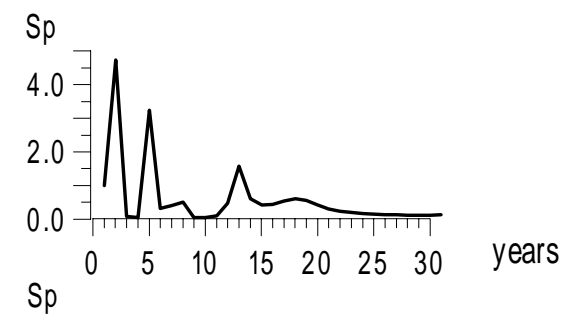

NINO 1+2

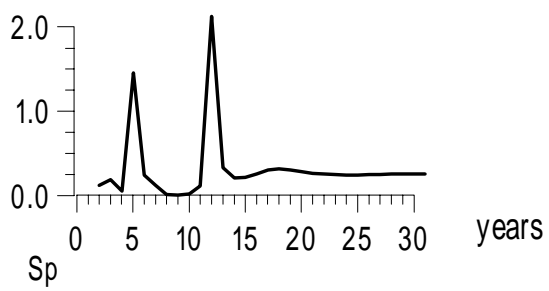

NINO 3+4

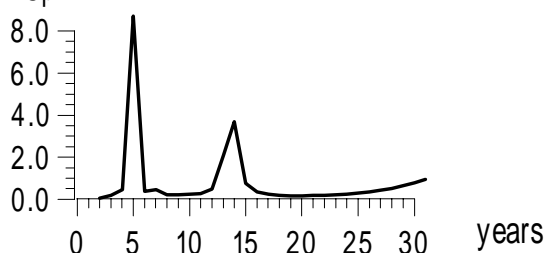

SOI

Sp

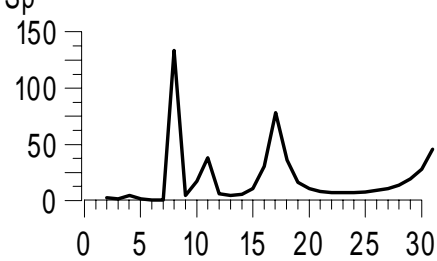

Sp

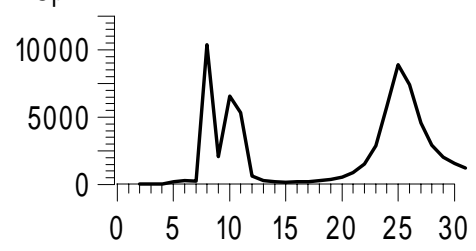

years

Ap-index

WOLF number

years

Fig. 2. MEM spectra of some yearly data: ENSO-indices, ap-index, Wolf-number.

period of 8 years (Othnes and Enochson, 1978). Dynamics of the long-period variations $(\mathrm{P}>8$ years) of ENSOand helio-geophysical indices are shown in Fig. 3. SOI data are changed in sign for a better comparison with the other data sets. The waves with period close to 20-22 years in the ENSO-data are visible. NINO $1+2$ and Ap-index curves are very similar.

Correlations were counted up for a quantitative estimation of similarity of the above mentioned curves (Table 2). Only data NINO $1+2$ correlates significantly with the Ap-index data. Also, the correlation coefficient in the time interval 1950-1970 is much higher than in that after 1970. The correlation between Wolf numbers and NINO $1+2$ is higher than between Wolf numbers and the other ENSO indices; moreover correlations are higher in the time interval 1974-1996 for all data. Correlation coefficients are higher for data from regions situated close to the coast of South America (NINO 1
dAp

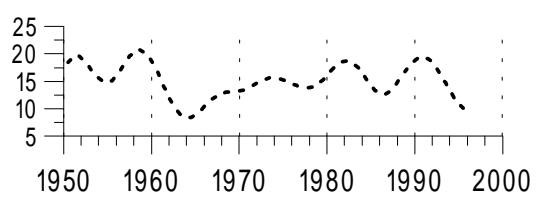

Ap-index

$\mathrm{dt}$, $\operatorname{deg} \mathrm{C}$

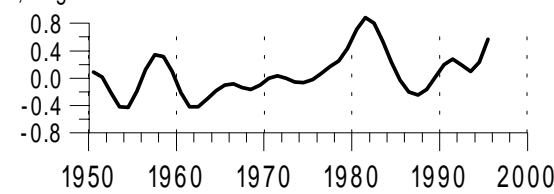

dW

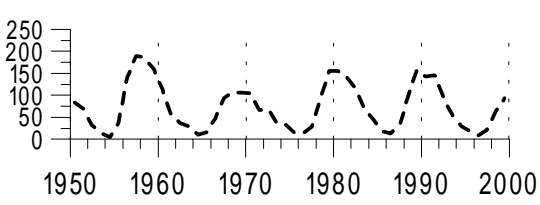

WOLF

dt, $\operatorname{deg} C$

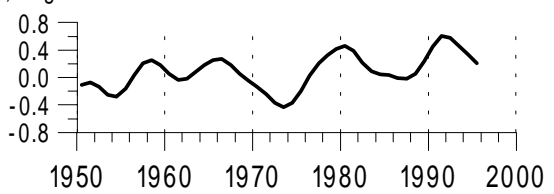

NINO 3+4

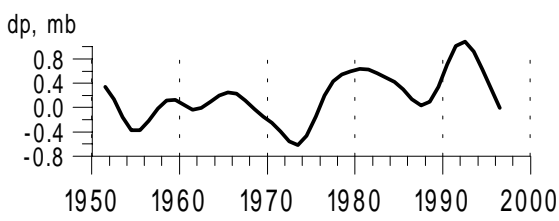

- SOI

Fig. 3. Low-frequency variations $(P>8$ years) of ENSO Data and helio-geophysical indices (Ap-index, Wolf-number); SOI data are changed in sign.

+2 and NINO 3). A phase shift between correlated data takes place in the middle of the 70-th. Wolf number is not a physical index of solar activity, i.e. a factor, which can have a physical effect on Earth processes. The physical agent that modulates long-period variations of ENSO phenomena is displaced in time by 1-2 years relative to the maximum Wolf number in the 11-year cycle.

The background magnetic field of the Sun changes sign close to a maximum of its 11-year cycle (Howard, 1974). The magnetic field reversal continues for 1 to 3 years. The 20-th solar cycle maximum, according to Wolf number, occurred in 1968-1969. The reverse of the polar magnetic field began at the end of 1969 and finished in the middle of 1970 and 1971 in the northern and southern hemispheres of the Sun, respectively. The reversal magnetic field of the Sun was opposite to the Earth's magnetic field, i.e. the northern and southern magnetic poles were located in the northern and southern hemisphere of the Sun (ftp:// ftp.ngdc.noaa.gov/STP/SOLAR_DATA/SUN_AS_A_STAR). The polarity of leading and tailing sunspots in bipolar groups and also the direction of the interplanetary magnetic field (IMF) were changed, too. The cycle of full reversal of 
Table 2. Correlations between long-period variations ( $\mathrm{P}>8$ years) of some ENSO data and indices of geomagnetic (Ap) and solar (Wolf-numbers) activity

$r$ - correlative coefficient, $\tau$ - lag, $p$ - confidence level

\begin{tabular}{lcccr}
\hline & Time interval & \multicolumn{3}{c}{ Ap } \\
& & $r$ & $\tau$, year & $p, \%$ \\
\hline NINO 1+2 & $1950-1994$ & 0.55 & 0 & 95 \\
\hline NINO 1+2 & $1950-1970$ & 0.74 & 0 & 95 \\
\hline NINO 1+2 & $1970-1996$ & 0.55 & 1 & $<90$ \\
\hline & & & & \\
\hline & & & W & \\
& & $r$ & $\tau$, year & $p, \%$ \\
\hline NINO 1 +2 & $1950-1996$ & 0.57 & 1 & 95 \\
\hline NINO 1 +2 & $1950-1973$ & 0.80 & 1 & 95 \\
\hline NINO 1 +2 & $1974-1996$ & 0.72 & 2 & 94 \\
\hline NINO 3 & $1950-1996$ & 0.50 & 0 & 95 \\
\hline NINO 3 & $1950-1975$ & 0.55 & 0 & 90 \\
\hline NINO 3 & $1975-1996$ & 0.82 & 1 & 95 \\
\hline NINO 3 +4 & $1950-1996$ & 0.48 & 0 & 93 \\
\hline NINO 3 +4 & $1950-1974$ & 0.43 & 0 & $<90$ \\
\hline NINO 3 +4 & $1974-1996$ & 0.71 & 1 & 90 \\
\hline
\end{tabular}

the solar magnetic field, or Hale's cycle, lasts 22-23 years (Vitinsky, 1973).

The 11-year and 22-year cycles of solar activity are reflected in the dynamics of many meteorological processes, namely, atmospheric temperature and pressure and precipitation. Correlations between hydrological and meteorological parameters on the one hand, and solar activity and geomagnetic field disturbance on the other, have different signs $(+o r-)$ and statistical significances in different regions of the Earth (Druzhinin, Sazonov, Jagodinsky, 1974; King, 1975; Ol'j, 1973; Solar-Terrestrial Influences on Weather and Climate, 1979). Moreover, infringement of connections takes place during a reversal of the solar magnetic field.

The precipitation in many regions of the Earth correlates with the 22-year cycle better than with the 11-year one. The yearly sum of precipitation is reflected in the width of year tree rings. Thus trees can give information about change of precipitation with a time (Bitvinskas, 1974; Roberts, 1975).

Analysis of the annual rainfall data sets in Brazil shows the 22-year period predominant. In the equatorial station Fortaleza $\left(\varphi=3^{\circ} 45^{\prime} S\right)$ the correlation coefficient between solar cycles and rainfall data is equal to -0.77 during $1849-1940$ and +0.80 during $1952-2000$. Correlation in the south latitude station Pelotas $\left(\varphi=31^{\circ} 45^{\prime} S\right)$ is equal to 0.60 for the time interval of $1893-1920$ and -0.84 for the time interval of 1929-2000. Also, analysis of short-term rainfall variation shows a significant increase of precipitation several days after crossing the magnetic sector boundary at the Earth (Spjeldvik et al., 2001).

The analysis of planetary fields of pressure shows that they are connected both with the 11-year and the 22-year solar cycles (Wagner, 1971). The atmospheric barometric centers,
$D(d t), \operatorname{deg} C$

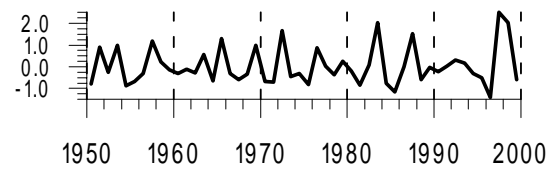

NINO 1+2

$D(d t), \operatorname{deg} C$

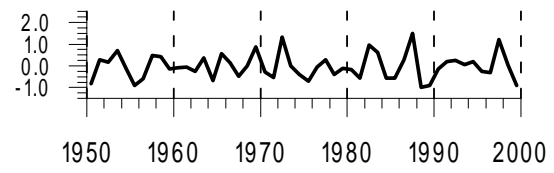

NINO 3+4

$D(d p), m b$

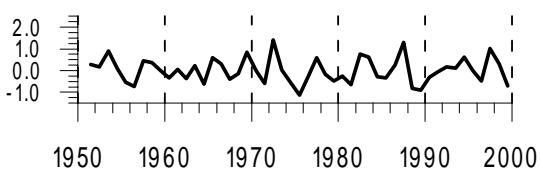

-SOI

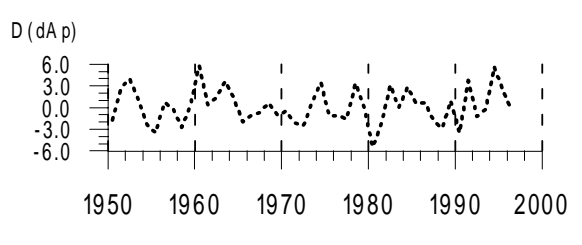

$D(d W)$

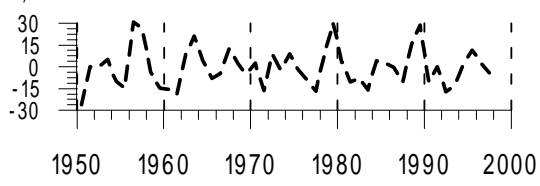

Wolf-

number

Fig. 4. Short-period oscillations $(\mathrm{P}<8$ years)of ENSO Data and helio-geophysical indices; deviations from long-period variations are shown on the $y$-axis; SOI data are changed in sign.

Icelandic and Aleut depressions, Pacific, Siberian, Azores anticyclones in the northern hemisphere, displace close to the maxima of 11-year solar cycles. The Azores and Icelandic barometric centers tend to displace on the east close to the maximum of a solar cycle (Herman and Goldberg, 1978). The clockwise circulation, connected with Azores anticyclone, causes passat winds in the north-east direction.

The response of barometric formations at the midday regions of the Earth (namely, recess or filling of cyclones or strengthening or destruction of anticyclones) depends upon tbe sign of the magnetic field of the sunspot which is crossing the central meridian of the Sun (Nuzhdina and Barkova, 1983). Spontaneous phenomena of solar activity (solar flares) and crossings by the Earth of an IMF sector boundary are accompanied by changes of atmospheric pressure and cyclonic activity in some regions Mustel, 1972; Roberts and Olsen, 1973; Herman and Goldberg, 1978). A low-pressure region in the gulf of Alaska is more significant, when the IMF is directed away from the Sun, than towards (Wilcox, 1978).

Solar-terrestrial connections that depend upon the sign of the IMF (or common solar magnetic field) can be explained 
Table 3. Spectra of coherency and phase between short-period oscillations $(\mathrm{P}<8$ years) of some ENSO data (NINO $1+2, \mathrm{NINO} 3+4$, SOI) and helio-physical indices (Ap-index, Wolf-numbers).

$\boldsymbol{q}$ - coherency coefficients (significant ones are indicated as bold \& italic); $\varphi$ - phases - months (phases are shown for significant coherency only)

\begin{tabular}{c|c|c|c|c|c|c|c|c}
\hline $\mathrm{N}$ & $f$ & $\mathrm{P}$, & \multicolumn{2}{|c|}{$\mathrm{dAp}-\mathrm{N} 1+2$} & \multicolumn{2}{c|}{$\mathrm{dAp}-\mathrm{N} 3+4$} & \multicolumn{2}{|c}{ dAp-SOI } \\
\cline { 4 - 9 } & $l / y$ & years & $q$ & $\varphi, m n$ & $q$ & $\varphi, m n$ & $q$ & $\varphi, m n$ \\
\hline 1 & .188 & 5.33 & .34 & - & .26 & - & .30 & - \\
2 & .281 & 3.56 & .42 & - & .35 & - & .31 & - \\
3 & .375 & 2.67 & $\mathbf{. 8 2}$ & $\mathbf{- 7 . 4} \pm \mathbf{2 . 0}$ & $\mathbf{. 8 5}$ & $\mathbf{- 6 . 9} \pm \mathbf{1 . 6}$ & $\mathbf{. 7 8}$ & $\mathbf{- 6 . 6} \pm \mathbf{2 . 1}$ \\
4 & .469 & 2.13 & .04 & - & .58 & - & .56 & - \\
5 & .563 & 1.78 & .33 & - &. $\mathbf{7 5}$ & $\mathbf{2 . 3} \pm \mathbf{1 . 6}$ & $\mathbf{. 9 0}$ & $\mathbf{2 . 0} \pm \mathbf{0 . 9}$ \\
6 & .656 & 1.53 & .20 & - & .50 & - & $\mathbf{. 8 0}$ & $\mathbf{- 0 . 5} \pm \mathbf{1 . 1}$ \\
7 & .750 & 1.33 & .33 & - & .34 & - & .10 & - \\
8 & .844 & 1.19 & .24 & - & $\mathbf{. 8 5}$ & $\mathbf{0 . 5} \pm \boldsymbol{0 . 8}$ & $\mathbf{. 8 6}$ & $\mathbf{0 . 3} \pm \boldsymbol{0 . 8}$ \\
9 & .958 & 1.07 & $\mathbf{. 9 0}$ & $\mathbf{- 1 . 2} \pm \mathbf{0 . 6}$ & $\mathbf{. 7 5}$ & $\mathbf{- 2 . 8} \pm \boldsymbol{0 . 9}$ & .34 & - \\
\hline
\end{tabular}

\begin{tabular}{c|c|c|c|c|c|c|c|c}
\hline $\mathrm{N}$ & $f$ & $\mathrm{P}$, & \multicolumn{2}{|c|}{$\mathrm{dW}-\mathrm{N} 1+2$} & \multicolumn{2}{c|}{ dW-N 3+4 } & \multicolumn{2}{c}{ dW-SOI } \\
\cline { 4 - 9 } & $l / y$ & years & $q$ & $\varphi, m n$ & $q$ & $\varphi, m n$ & $q$ & $\varphi, m n$ \\
\hline 1 & .188 & 5.33 & .78 & $\mathbf{- 1 . 3} \pm \mathbf{4 . 4}$ & .63 & - & $\mathbf{. 7 3}$ & $\mathbf{- 0 . 9} \pm \mathbf{5 . 0}$ \\
2 & .281 & 3.56 & .34 & - & .36 & - & .23 & - \\
3 & .375 & 2.67 & .30 & - & .44 & - & .40 & - \\
4 & .469 & 2.13 & $\mathbf{. 7 8}$ & $\mathbf{- 5 . 5} \pm \mathbf{1 . 8}$ & .46 & - & .46 & - \\
5 & .563 & 1.78 & .60 & - & $\mathbf{. 9 5}$ & $\mathbf{- 4 . 7} \pm \mathbf{0 . 3}$ & $\mathbf{. 9 0}$ & $\mathbf{- 4 . 4} \pm \mathbf{0 . 9}$ \\
6 & .656 & 1.53 & $\mathbf{. 7 0}$ & $\mathbf{- 2 . 7} \pm \mathbf{1 . 5}$ & .38 & - & $\mathbf{. 7 0}$ & $\mathbf{1 . 4} \pm \mathbf{1 . 5}$ \\
7 & .750 & 1.33 & $\mathbf{. 8 2}$ & $\mathbf{- 3 . 2} \pm \mathbf{1 . 0}$ & .18 & - & .65 & - \\
8 & .844 & 1.19 & $\mathbf{. 9 7}$ & $\mathbf{- 1 . 8} \pm \mathbf{0 . 3}$ & $\mathbf{. 8 3}$ & $\mathbf{- 2 . 5} \pm \mathbf{0 . 8}$ & $\mathbf{. 7 8}$ & $\mathbf{1 . 9} \pm \mathbf{1 . 1}$ \\
9 & .958 & 1.07 & $\mathbf{. 6 8}$ & $\mathbf{- 1 . 2} \pm \mathbf{1 . 1}$ & $\mathbf{. 7 5}$ & $\mathbf{1 . 5} \pm \mathbf{0 . 9}$ & .32 & - \\
\hline
\end{tabular}

by the influence of charged particles in the Earth's atmosphere. The IMF modulates a flow of galactic cosmic rays (GCR) of certain energy to the Earth's atmosphere. Fast protons from solar flares and GCR of low energy $\left(2 t o 6 \times 10^{9} \mathrm{eV}\right)$ are absorbed in the low stratosphere and upper troposphere close to the ozone maximum (Vitinsky et al., 1976). Consequently, the $\mathrm{NO}_{\mathrm{x}}$ concentration in the middle atmosphere is increasing and the total stratospheric ozone is decreasing. The largest solar proton events in the past thirty years, October 1989, August 1972 and July 2000, caused ozone depletions $>10 \%$ for some days to weeks (Jackman et al., 2001). The absorption of fast charged particles proceeds most effectively in the atmosphere at high geomagnetic latitudes $\left(>60^{\circ}\right)$ but this effect can be found in lower latitudes due to atmospheric circulation. It is known that stratospheric ozone is an important climatic factor.

Air ions, which appear as a result of ionization of the atmospheric molecules by GCR, can be considered as charged clusters or condensation nuclei for rain-cloud formation. So, correlation between the solar magnetic field, IMF, ionization rate in the troposphere, clouds and the amount of precipitation has been found (Fangqun Yu, 2001; Pudovkin, 1996).

When the Earth crosses a sector boundary from negative to positive, thunderstorm activity decreases (Mullayarov et al., 2001). It is also shown that thunderstorm activity decreases to a minimum on the third day after a proton flare and then increases on the fourth or fifth day.

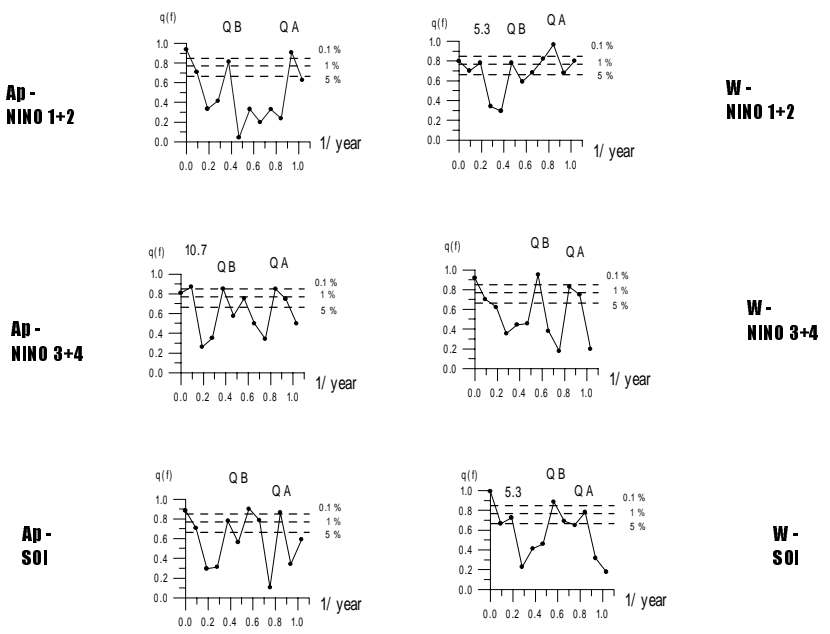

Fig. 5. Spectra of coherency of short period oscillations ( $\mathrm{P}<8$ years) of ENSO Data and helio-geophysical indices; QB Cycle: 1.8-2.12.7 years; QA cycle: $1.1-1.2$ years.

3.2 Connections between ENSO-data and solar and geomagnetic indices in the high-frequency interval of oscillations

To compare high-frequency oscillations $(\mathrm{P}<8$ years $)$ in ENSO-data and helio-geophysical indices, low-frequency oscillations were first eliminated from the above-mentioned data sets. The quarter-of-year data were used in calcula- 
tions. At first low-frequency BWF with cut-off period of 8 years (96 months) was applied and then the result of filtering was subtracted from the initial data. Long-term dynamics of short-period oscillations of some ENSO data as well as Ap-index and Wolf numbers are shown in Fig. 4. SOI data have been reversed in sign for comparison. There is no significant correlation between filtered ENSO data and helio-geophysical parameters. To investigate connections between the short-period oscillations of ENSO data and geoheliophysical indices, cross-spectral analysis was applied. Time data were transformed to frequency by Fast Fourier Transformation and then spectra of coherency and phase were calculated (Othnes and Enochson, 1978). The results are presented in Fig. 5 and Table 3.

$\mathrm{QB}(\mathrm{P}=1.78 ; 2.13 ; 2.67$ years $)$ and quasi-annual (QA) $(1.07 ; 1.19 ; 1.33$ years) cycles are presented in ENSO data and Ap-geomagnetic index, as well as in ENSO data and Wolf-numbers, with the high coherency. 5.3-year oscillation, or the first subharmonic of the 11-year solar cycle is coherent in ENSO and Wolf number data.

Spectra of coherency and phase are shown in Table 3. Phases are indicated for significant coherency only. QA oscillations in ENSO and helio-geophysical data are going without essential phase shift. Oscillations with a period of 5.3 year in ENSO and Wolf-number data proceed with a phase shift of several months.

\section{Conclusions}

Analysis of ENSO data together with helio-geophysical indices (Wolf number, Ap-geomagnetic index) for the period 1950-1999 was carried out. This enabled us to draw the following conclusions:

- Spectra of ENSO indices show two main spectral bands, namely, long-period and short-period oscillations in the period ranges 10-23 and 2-7 years, respectively. Shortperiod oscillations include subharmonics of the solar cycle (5-6 years), QB ( $\mathrm{P}=1.78 ; 2.13,2.67$ years), QA (1.07; $1.19 ; 1.33$ years) and quasi-triennial (3.5 years) cycles.

- Weak correlations occur between long-period variations of ENSO data and the Ap-index of geomagnetic disturbance, ENSO and Wolf-number data. At the beginning of the 70-th phase shift between ENSO and heliogeophysical data sets occurs. At that time the background solar magnetic field was reversed. Full reversal of the solar magnetic field constitutes the 22-year solar magnetic cycle (Hale's cycle). The sign and direction of the IMF also changes during that period. Obviously, solar-terrestrial connections are realized by means of the IMF. Many meteorological and climatic parameters correlate better with the 22-year solar cycle than with the 11-year solar cycle.

- QB and QA oscillations in ENSO data are coherent with the same oscillation in Ap-index and Wolf number data. 5.3-year oscillation is coherent in ENSO and Wolf number data.

- In our opinion, cyclic dynamics of ENSO phenomena are due to solar activity and geomagnetic variations. It is background long-period variations on which highfrequency oscillations are imposed.

\section{References}

Angell, J. K.: Evidence of a relation between El Niño and QBO and for an El Niño in 1991-92, Geoph. Res. Letters, 19, 285-288, 1992.

Bitvinskas, O. O.: Dendroclimatic researches (in Russian), Leningrad, Hydrometeoizdat, 172, 1974.

Diamantides, N. D.: Long-term solar activity and terrestrial connections, Part II: at the beckon of the Sun?, Ann. Geophysicae, 16, 492-509, 1998.

Druzhinin, I. P., Sazonov, B. I., and Jagodinsky, B. N.: The Spacethe Earth. Predictions, Moscow, 288, 1974.

Enfield, D. B.: El Niño, Past and Present, Rev. of Geophys., 27, 59-187, 1989.

Fangqun Yu: Galactic cosmic rays, particle formation, natural variability of global cloud properties, and climate implications. The effect of Solar Proton Events on Ozone and Other Constitutions in the Middle Atmosphere. In: ISCS 2001 Abstracts. Solar Variability, Climate and Space Weather, (http://rise.hao.ucar.edu/iscs/abstract.html).

Graham, N. E. and White, W. B.: The El Niño cycle: Pacific Ocean - atmospheric system, Science, 240, 1293-1302, 1988.

Herman, J. R. and Goldberg, R. A.: Sun, Weather, and Climate. National Aeronautics and Space Administrations, Washington, D.C., 305, 1978.

Howard, R.: Studies of Solar magnetic fields. 1. The average field strengths, Solar Phys., 38, 283-299, 1974.

Jackman, C. H., McPeters, R. D., Labow, G. J., Fleming, E. J., Russel, J. M., and Praderas, C. J.: The Effect of Solar Proton Events on Ozone and Other Constitutions in the Middle Atmosphere, In: ISCS 2001 (International Solar Cycle Studies 2001) Abstracts. Solar Variability, Climate and Space Weather, (http://rise.hao.ucar.edu/iscs/abstract.html).

King, J. W.: Sun-weather relationships, Aeronautics and Astronautics, 13, 10-19, 1975.

Lacoss, R. T.: Data adaptive spectral analysis methods, Geophysics, 36, 661-675, 1971.

McCreary, I. P.: A model of tropical ocean-atmosphere interaction, Mon. Weather Rev., III, 370-387, 1983.

Mullayarov, V. A., Kozlov, V. I., and Karimov, R. R.: Relation of Thunderstorm Activity to Cosmic Ray Variations. In: ISCS 2001 Abstracts. Solar Variability, Climate and Space Weather, (http://rise.hao.ucar.edu/iscs/abstract.html).

Mustel, E. R.: On the reality of the influence of solar corpuscular streams upon the lower layer of the earth's atmosphere. In: The Astronomical Union of Acad. Sciences., Moscow, 24, 5-55, 1972.

Nuzhdina, M. A. and Barkova, N. A.: Tropospoheric response on Sunspot passage of the Solar Central Meridian. Solar Data, Leningrad, 7, 105-112, 1983.

Ol'j, A. I.: Rhythmic processes in the Earth atmosphere. In: The Reports on annual readings on memory of L. S. Berg, 1967-1971 (in Russian), Leningrad, Science, 148-164, 1973. 
Othnes, R. K. and Enochson, L.: Applied Time Series Analysis, V. 1. A Wiley-Interscience Publication, New York - Chichester - Brisbane - Toronto, 428, 1978.

Philander, S. G. H.: El Niño, La Niña and the Southern Oscillation, Academic Press, San Diego, CA, 289, 1990.

Pudovkin, M. I.: Influence of solar flares and flare-associated streams on the state of the lower atmosphere, Ann. Geophysicae, Suppl. III , 14, C 759, 1996.

Rasmusson, E. M. and Carpenter, T. C.: Variations in tropical sea surface temperature and surface wind fields associated with the Southern Oscillation/El Niño, Mon. Weather Rev., 110, 354-382, 1982.

Roberts, W. O.: Relationship between solar activity and climate change. Goddard Space Flight Center, Special Report, NASA, 13, 1975.

Roberts, W. O. and Olsen, R. H.: New evidence for effects of variable solar corpuscular emission on the weather, Rev. Geophys. Space Phys., 11, 731-740, 1973.

Solar-Terrestrial Influences on Weather and Climate. Proceedings of a Symposium/Workshop held at the Fewcett Center for Tomorrow, The Ohio State University, Columbus, Ohio, 24-28 August, 1978. Edd.: Dordrecht: Holland; Boston: USA; London: UK, 384, 1979.

Spjeldvik, W. A., Almeida, A., Gusev, A., Martin, I. M., and Pugacheva, G.: New Evidence of Space Weather Impact on the
Terrestrial Weather and Climate in the Earth's Southern Hemisphere. In: ISCS 2001 Abstracts. Solar Variability, Climate and Space Weather, (http://rise.hao.ucar.edu/iscs/abstract.html).

Trenberth, K. E. and Hoar, T. J.: The 1990-1995 El Niño - Southern Oscillation Event: Longest on record. Geoph. Res. Letters, 23, 57-60, 1996.

Vitinsky, Yu. I.: Cyclisity and forecast of solar activity (in Russian), Science, Leningrad, 258, 1973.

Vitinsky, Yu. I., Oll, A. I., and Sazonov, B. I.: The Sun and the Earth' atmosphere (in Russian). Hydrometeoizdat, Leningrad, 351, 1976.

Wagner, A. J.: Long-period variations in seasonal sea-level pressure over the Northern Hemisphere, Month. Weather Rev., 99, 49-66, 1971.

Walker, D. A.: Seismicity of the East Pacific Rise: Correlations with the Southern Oscillation Index, EOS Trans. AGU, 69, 857-867, 1988.

Walker, D. A.: More evidence indicates link between El Niños and seismisity, EOS Trans., 76 (4), 33-36, 1995.

Wilcox, J. M.: Influence of the Solar magnetic field on the troposphere circulation. In: Solar-Terrestrial Influences on Weather and Climate, Columbus, Ohio, 175-186, 1978.

Zebiak, S. E. and Cane, M. E.: A model El Niño - Southern Oscillation, Mon. Weather Rev., 115, 2262-2278, 1987. 